\title{
METODOLOGIAS PARA ANÁLISE DO DESCONFORTO VISUAL EM AMBIENTES DE TRABALHO: UMA REVISÃO BIBLIOGRÁFICA
}

\section{METHODOLOGIES FOR ANALYSIS OF VISUAL DESCONFORT IN WORKING ENVIRONMENTS: A BIBLIOGRAPHICAL REVIEW}

\author{
Giovana Mara Zugliani Bortolan ${ }^{1}$, Lic. \\ Marcelo Gitirana Gomes Ferreira ${ }^{2}$, Dr. \\ Flávio Anthero Nunes Vianna dos Santos³, Dr. \\ (1) Universidade do Estado de Santa Catarina (UDESC) \\ e-mail: gmzugliani@gmail.com \\ (2) Universidade do Estado de Santa Catarina (UDESC) \\ e-mail: marcelo.gitirana@gmail.com \\ (3) Universidade do Estado de Santa Catarina (UDESC) \\ e-mail: flavioanvs@hotmail.com
}

Palavras-chave: métodos, metodologias, desconforto visual, conforto visual, ambiente de trabalho

Resumo: O artigo objetivou identificar e reunir métodos de análise do desconforto visual, de modo que estes possam ser aplicados em ambientes de trabalho. Através de uma revisão sistemática bibliográfica, espera-se contribuir e orientar pesquisadores e profissionais na tomada de decisões projetuais, em fase inicial ou de projetos já construídos.

Key-words: methods, methodologies, visual discomfort, visual comfort, working environments

Abstract: The article aimed to identify methods of analysis of visual discomfort, so that they can be applied in workplaces. Through a systematic bibliographical review, it is hoped to contribute and guide researchers and professionals in the making of design decisions, in an initial phase or of projects already constructed.

\section{Introdução}

O processo de design, em geral, parte de uma necessidade humana, ou seja, do que o mercado realmente necessita, onde surgem os principais problemas que o design precisa criar ou melhorar. Através dos métodos, técnicas e ferramentas, o 


\section{$16^{\circ}$ \\ ERGODESIGN USIHC CINAHPA}

design busca a organização e sistematização para reproduzir resultados, ou seja, a inovação de produtos e serviços, através da criatividade e adequação (SANTOS, 2016).

Sendo assim, o processo de design deve ser: sistemático e organizado de modo que seja capaz de fornecer resultados. É para isso que são utilizados os métodos de projetos, ferramentas e técnicas de exploração. Oliveira e Mont'Alvão (2014) propõem distinguir os termos método e metodologia para um melhor entendimento e direcionamento da pesquisa. Por método de projeto entendemos que é "uma forma particular de procedimento para realizar algo, especialmente sistemático" (OLIVEIRA e MONT'ALVÃO, 2014, p. 500). Já a metodologia é um conjunto de operações, regras e postulados utilizados por uma disciplina; necessárias para a realização do projeto, dispostas de forma lógica e coerente (SANTOS, 2016).

A metodologia auxilia na estruturação do projeto, na definição e facilitam na organização do problema solucionando-os em partes com mais eficiência, rapidez e segurança e reduz as incertezas aumentando a sua qualidade. Vários autores e pesquisadores criaram e utilizaram de métodos muito diversos, cada qual com suas abordagens, porém não existe o melhor ou único método, o que existe é o mais adequado para uma determinada situação e realidade.

Diante dos desafios atuais em propor melhorias na qualidade de vida de trabalhadores, combatendo assim, problemas físicos e/ou cognitivos relacionados ao trabalho, e da formação de profissionais de design que contemplem as pesquisas em ergonomia, a grande questão está no auxílio à efetiva integração deste profissional às novas necessidades dos ambientes de trabalho. Partindo deste conceito é que o presente artigo propõe identificar e reunir os principais métodos de análise do desconforto visual, de modo que estes possam ser aplicados em ambientes de trabalho.

Para que houvesse um maior direcionamento e clareza no momento da pesquisa, realizou-se um $16^{\circ}$ Ergodesign - Congresso Internacional de Ergonomia e Usabilidade de Interfaces Humano Tecnológica: Produto, Informações Ambientes Construídos e Transporte

$16^{\circ}$ USIHC - Congresso Internacional de Ergonomia e Usabilidade de Interfaces Humano Computador

CINAHPA | 2017 - Congresso Internacional de Ambientes Hipermídia para Aprendizagem.

levantamento bibliográfico sobre métodos, desconforto visual, ambientes de trabalho e iluminação artificial através de uma revisão sistemática bibliográfica, para assim construir um pensamento consolidado e guiar projetos de iluminação para proporcionar um conforto maior a estes trabalhadores em seus locais de trabalho.

\section{1 (Des) Conforto Visual}

O conforto é visto como comodidade, apoio, consolo, alívio, bem-estar. Um conceito muito amplo, que dá margens a diferentes interpretações e percepções. Uma definição amplamente aceita de conforto humano não existe, mas várias métricas têm sido desenvolvidas para quantificar o quanto os usuários apreciam ambientes (IACOMUSSI $e t$ $a l, 2015)$.

Van Der Linden, Guimarães e Tabasnik (2005) conceituam o conforto como subjetivo, porém depende em grande parte da percepção da pessoa que está vivenciando a situação, não existindo uma definição universalmente aceita. Se conforto é uma condição para que se alcance o bem-estar e bemestar configura-se em uma necessidade humana, logo conclui-se que o conforto é fator fundamental para que um indivíduo tenha motivação (FERRARI et al, 2013).

Para Rodríguez et al (2015) o conforto pode ser elucidado como uma condição subjetiva de bemestar induzido pelo ambiente visual, e embora haja um fator psicológico intimamente relacionado com conforto visual, é possível realizar sua avaliação através de algumas propriedades físicas do ambiente.

Slater (1985) definiu conforto como "um estado prazeroso de harmonia fisiológica, física e psicológica entre o ser humano e o ambiente", ou seja, esta ideia indica a necessidade de que todas as dimensões sejam atendidas: "Os aspectos físicos do conforto correspondem à interação com o ambiente e seus efeitos nas dimensões fisiológicas e psicológicas" (VAN DER LINDEN, GUIMARÃES e TABASNIK, 2005, p.2).

O conforto visual também pode ser descrito como
Realização:

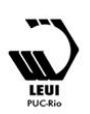




\section{$16^{\circ}$ \\ ERGODESIGN USIHC CINAHPA}

uma relação entre a iluminação e a visibilidade tendo como objetivo o desenvolvimento das atividades com maior acuidade visual, menos esforço e sem prejuízos à vista (LAMBERTS et al., 2014). Neste sentido, SHMID (2005) complementa afirmando que as condições de conforto visual podem ser resumidas no ajuste dos níveis absolutos e relativos de brilho das coisas aos propósitos que temos nos ambientes.

Boyce (2003) expõe de forma lógica que conforto visual é nada mais que a ausência de desconforto visual, pois as condições de iluminação que causam o desconforto podem ser manipuladas depois que todas as fontes de desconforto forem eliminadas. $\mathrm{O}$ autor também argumenta que o desconforto visual depende de três variáveis: o indivíduo, que neste caso fica a critério pessoal se é desconforto visual ou não; o contexto, condições de iluminação que podem ser desconfortáveis em uma aplicação podem não ser consideradas desconfortáveis em outro, e o desempenho visual que é restrito a área de trabalho específica, de modo que os aspectos de iluminação afetam o desconforto visual e pode ocorrer dentro do espaço iluminado.

\section{Método}

Para o desenvolvimento do presente artigo, foi utilizada como procedimento metodológico a revisão sistemática bibliográfica (RSB) que segundo Ferenhof e Fernandes (2016, p. 2) é um método de investigação científica "com um processo rigoroso e explícito para identificar, selecionar, coletar dados, analisar e descrever as contribuições relevantes a pesquisa".

Para nortear a revisão sistemática, foi definido o seguinte problema: Quais principais métodos vêm sendo utilizados para a análise do desconforto visual aplicáveis a ambientes de trabalho?

Assim, foram definidas as palavras chaves: métodos, (Des) conforto visual, ambientes de trabalho e iluminação artificial, que foram utilizadas para a realização do levantamento bibliográfico para atender o objetivo deste artigo, sendo este, identificar e reunir os principais $16^{\circ}$ Ergodesign - Congresso Internacional de Ergonomia e Usabilidade de Interfaces Humano Tecnológica: Produto, Informações Ambientes Construídos e Transporte

$16^{\circ}$ USIHC - Congresso Internacional de Ergonomia e Usabilidade de Interfaces Humano Computador

CINAHPA | 2017 - Congresso Internacional de Ambientes Hipermídia para Aprendizagem.

métodos de análise do desconforto visual, de modo que estes possam ser aplicados em ambientes de trabalho. Antes de iniciar a RBS, foram realizadas buscas exploratórias (pesquisa isolada, sem critérios específicos utilizados na revisão sistemática) e foram encontrados dois artigos (Tabela 1) que condizem com o tema abordado e são complementares à revisão sistemática.

Tabela 1. Bibliografia complementar.

\begin{tabular}{lll}
\hline \multicolumn{1}{c}{ Título } & Autores & Tipo/Ano \\
\hline & & \\
$\begin{array}{l}\text { Sensitive physiological indicators } \\
\text { for human visual comfort } \\
\text { evaluation }\end{array}$ & SUN,C.; LIAN, Z. & Artigo/2016 \\
& & \\
\hline & & \\
$\begin{array}{l}\text { Effects of Light's Colour } \\
\text { Temperatures on Visual Comfort }\end{array}$ & $\begin{array}{l}\text { SHAMSUL, et al } \\
\text { Level, Task Performances, and } \\
\text { Alertness among Students }\end{array}$ & \\
& & \\
& & \\
\end{tabular}

Fonte: Elaborado pelos autores, 2016

Para a revisão sistemática, as bases de dados utilizadas foram a Scopus e Web of Science, uma plataforma que oferece um conjunto de bases de dados para estudo e análise de citações de artigos, publicações e agências de fomento. Para iniciar a pesquisa na base de dado, foram definidos alguns critérios para a seleção dos artigos: determinação das palavras-chaves no idioma inglês, seleção de artigos recentes (últimos dez anos); leitura de títulos, abstracts, leitura diagonal (introdução, conclusão e métodos) e leitura completa do artigo. Os critérios de seleção foram organizados na tabela a seguir (Tabela 2).

Tabela 2. Síntese de métodos e técnicas utilizadas.

\begin{tabular}{ll} 
Métodos e técnicas & \multicolumn{1}{c}{ Resultados } \\
de pesquisa & \\
\hline $\begin{array}{l}\text { Determinação das palavras } \\
\text { chaves no idioma inglês: } \\
\text { methods, visual discomfort, }\end{array}$ & $\begin{array}{l}\text { Organização e combinação } \\
\text { das palavras chaves, a fim } \\
\text { de reduzir o número de }\end{array}$ \\
\hline
\end{tabular}

Realização:

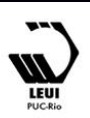


$16^{\circ}$ Ergodesign - Congresso Internacional de Ergonomia e Usabilidade de

\section{$16^{\circ}$ \\ ERGODESIGN \\ USIHC CINAHPA} Interfaces Humano Tecnológica: Produto, Informações Ambientes Construídos e Transporte

$16^{\circ}$ USIHC - Congresso Internacional de Ergonomia e Usabilidade de Interfaces Humano Computador

CINAHPA | 2017 - Congresso Internacional de Ambientes Hipermídia para Aprendizagem.

\begin{tabular}{ll} 
workplaces, artificial lighting & artigos. \\
\hline Organização dos artigos & $\begin{array}{l}\text { Selecionados os artigos dos } \\
\text { últimos dez anos (dentro do } \\
\text { tema proposto) }\end{array}$ \\
\hline Seleção dos artigos & \\
\hline Critérios de exclusão & $\begin{array}{l}\text { Título e palavras chaves } \\
\text { foram retirados os artigos } \\
\text { fora do contexto da } \\
\text { pesquisa, sem cunho } \\
\text { científico, com mais de dez } \\
\text { anos de publicação e os que } \\
\text { não possuíam acesso } \\
\text { gratuito. }\end{array}$ \\
\hline
\end{tabular}

Fonte: Elaborado pelos autores, 2016

Na base de dados Scopus e Web of Science, a pesquisa foi realizada no dia 06 de novembro de 2016. A busca gerou na primeira pesquisa, 163 documentos, e nesta etapa não foram aplicados filtros. Após a segunda triagem, considerando os critérios de exclusão indicados na tabela 2, o resultado foram 22 documentos.

Posteriormente, foram analisados os títulos dos documentos e respectivamente seus resumos, sendo retirados da pesquisa aqueles que não se adequavam em função de seu tema, sua abordagem e método, sendo mantidos somente os que avaliaram de maneira direta o desconforto visual. Resultaram apenas oito documentos, e os mesmos foram utilizados para a revisão sistemática do assunto a ser explorado. Os documentos utilizados sua relevância para a pesquisa, considerando principalmente a qualidade dos textos e o seu tema, e estão descritos na tabela 3 .

Tabela 3. Resultado da seleção de pesquisa na base de dados Scopus e Web of Science na revisão metodológica foram eleitos conforme

\begin{tabular}{lll}
\hline Título & Autores & Ano \\
\hline
\end{tabular}

Illuminance Distributions, Visual Response and limits for conservation of exhibits in admiral Cheng Ho gallery, Malaysia 2011

Lighting of Workplaces and Health Risks

REINHOLD, K;

2009 TINT, $\mathrm{P}$.

Investigating the use of an
adjustment task to set the
preferred illuminance in a
workplace environment
Personal environmental control:
Effects of pre-set conditions for
heating and lighting on personal
settings, task performance and
comfort experience

LOGADÓTTIR, Á.; CHRISTOFFERESE

2011 N, J.; FOTIOS, S.A.

KORTE, E. M,; et a 2015

Lighting and discomfort in the classroom

WINTERBOTTOM, 2009 M,; WILKINS, A
2011

BELLIA, L.; $\begin{array}{ll}\text { through HDR imaging } & \text { MUSTO, M } \\ \text { photometry in scholastic } & \text { SPADA, G. }\end{array}$ environment

Effects of Indoor Lighting on Occupants' Visual Comfort and Eye Health in a Green Building $\mathrm{T}$.

Investigation of the potential use

CHOI, J.; ZHU, R 2015 of human eye pupil sizes to estimate visual sensations in the workplace environment
HWANG, T.; KIM, J. 2011 


\section{$16^{\circ}$ \\ ERGODESIGN USIHC CINAHPA}

\section{Resultado e Discussão}

A seguir, uma análise dos objetivos, métodos e resultados de cada artigo selecionado na revisão bibliográfica sistemática.

Ahamadi, N; Ahamadi, S. e Talib, A. (2009) avaliaram os níveis e distribuição da luz natural e artificial e analisaram a resposta visual dos visitantes e feedback sobre as condições das exposições nas vitrines. Como método foi utilizado o luxímetro para medir a iluminância e questionário sobre resposta visual. Foram constatadas algumas irregularidades como excesso de iluminação e necessidade de ajustes, porém os resultados indicam a indispensabilidade de um estudo mais aprofundado com uma maior investigação e dados mais detalhados.

Um outro estudo que avaliou a iluminância no ambiente, porém, neste caso foi detectada insuficiente, e com risco de comprometimento na saúde como: estresse visual e desconforto, foi realizado por Reinhold, K e Tint, P. (2009). O objetivo era identificar os principais riscos presentes no ambiente de trabalho e avaliar suas características através do método de avaliação de riscos e estudo de caso em 18 companhias de diversas industrias: impressão, vestuário, madeira, plástico e mecânica.

Este método avaliou os riscos dos níveis de iluminação em cinco escalas: ótima, risco tolerável; normal, risco justificado; condicional, risco não justificado; e por último, em duas etapas, o limite critico: risco inadmissível e intolerável. Para fazer as medidas de iluminação no ambiente de trabalho foi utilizado a norma técnica DIN 5356:2006 - A iluminação artificial - Parte 6: Medição e avaliação. Nas empresas estonianas investigadas a iluminação era mal organizada e insuficiente, e apenas na companhia mecânica foi detectado reflexos e flickers. Os riscos de problemas de saúde foram justificáveis e dentro dos padrões aceitáveis.

Logadóttir, A; Christofferesen, J. e Fotios, S. A. (2011) realizaram um experimento para examinar a preferência dos usuários sobre os níveis de $16^{\circ}$ Ergodesign - Congresso Internacional de Ergonomia e Usabilidade de Interfaces Humano Tecnológica: Produto, Informações Ambientes Construídos e Transporte

$16^{\circ}$ USIHC - Congresso Internacional de Ergonomia e Usabilidade de Interfaces Humano Computador

CINAHPA | 2017 - Congresso Internacional de Ambientes Hipermídia para Aprendizagem. iluminação utilizando o método de ajuste. Este, consistia em duas salas idênticas lado a lado, e foram planejadas e mobiliadas como um escritório de uma pessoa. Foi dado a cobaia o controle sobre o estímulo, geralmente envolvendo variações em luminosidade, e as vezes correlacionadas a temperatura de cor, e esta era instruída para definir a luminosidade para seu nível preferencial.

A estimativa de luminância preferencial foi afetada com a variedade de iluminância disponível em uma escala aumentada que também aumentou a luminância. Os resultados experimentais confirmaram que o espectro do estímulo e a ancora tem efeitos significativos na resposta da tarefa de ajuste confirmando a importância de considerar e relatar estas variáveis ao determinar a preferência dos usuários com este método.

Korte, E. M et al. (2015) utilizaram um experimento de uma estação de trabalho com iluminação e aquecimento controlado individualmente. Vinte pessoas realizaram tarefas padronizadas neste protótipo com controles individualizados de aquecimento e iluminação em uma sala climatizada. Os resultados mostraram que as configurações preferenciais pessoais dependem dos valores iniciais, pré-definidos de calor e iluminância. Valores elevados tanto em aquecimento como em iluminância, geraram resultados altos de ajustes.

Após o ajuste o conforto visual era mais alto, mas não dependente dos valores pré-estabelecidos e nenhuma tarefa individual foi afetada negativamente. Providenciar um ambiente pessoal com controle individual e a maneira como esses conceitos e interfaces são projetados tem um papel significante no comportamento dos usuários e suas preferências, ou seja, a pessoa tendo o controle de manipular o ambiente de acordo com sua preferência, se sente mais confortável além de gerar economia de energia.

Winterbottom, M. e Wilkins, A. (2009) realizaram um experimento em 90 salas de aula, em onze escolas com condições inadequadas. Os aspectos e design dos ambientes provocavam desconforto e impediam a performance das tarefas, através de
Realização:

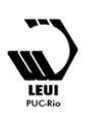




\section{$16^{\circ}$ \\ ERGODESIGN USIHC CINAHPA}

reflexos e flickers imperceptíveis de lâmpadas fluorescentes de $100 \mathrm{~Hz}$. Em cada sala foi feito um esboço do espaço, bem como as lâmpadas, luminárias e dimensões do local. Foram medidos os flickers imperceptíveis das lâmpadas com o aparelho "servo-controlled rotating shutter" programado para 104 oclusões por segundo. A luminância foi medida por um luxímetro posicionado nas mesas e foi marcado com 4 condições: luzes acesas e persianas abertas, luzes apagadas e persianas abertas, luzes acesas e persianas fechadas e por último, luzes apagadas e persianas fechadas.

Nos resultados foram identificados problemas na sala de aula ocasionados pela tomada de decisões ruins. Na maioria dos casos, ações para corrigir o problema são simples e quaisquer custos seriam compensados a médio prazo como: aumento de eficiência, redução de desperdício e benefícios em termos de saúde dos estudantes e professores. As salas de aula são iluminadas com luzes fluorescentes ineficientes que causam dores de cabeça e impedem a performance visual; e foram observadas que as combinações de baixa frequência e lâmpadas com alta temperatura de cor devem ser evitadas.

Foi percebido também que $80 \%$ das salas de aula são iluminadas com $100 \mathrm{~Hz}$ de iluminação e por questões de conforto deve-se optar por lâmpadas com temperatura de cor de $3.500 \mathrm{k}$. Outro ponto observado foi o excesso de iluminação natural e artificial. As salas devem ter luminárias com dimers automáticos sem flickers e as lâmpadas fluorescente podem causar dores de cabeça e prejudicar o desempenho visual. Foram constatados níveis excedidos e diminuição do conforto visual e a iluminação não pode ser adequada devido à infraestrutura do local.

Bellia, L.; Musto, M; Spada, G. (2011) analisaram a luminância de salas de aula utilizando o Método HDR/MATLAB e compararam com o método tradicional que é o luxímetro. Foi observado que a diferença das medidas obtidas entre o método tradicional e o HDR ficaram limitadas em $20 \%$ em 97,7\% dos casos com iluminação natural e 98,5\% dos casos com iluminação natural e artificial. As $16^{\circ}$ Ergodesign - Congresso Internacional de Ergonomia e Usabilidade de Interfaces Humano Tecnológica: Produto, Informações Ambientes Construídos e Transporte

$16^{\circ}$ USIHC - Congresso Internacional de Ergonomia e Usabilidade de Interfaces Humano Computador

CINAHPA | 2017 - Congresso Internacional de Ambientes Hipermídia para Aprendizagem. medidas obtidas pelo método HDR estão de comum acordo com o método tradicional, exceto em fontes de luz que atingem o alvo (próximo de janelas). São necessários mais testes e pesquisas para melhorar o processo de medidas.

Hwang, T., KIM, J. T. (2011) mediram a influência da iluminação interior na saúde visual e no conforto dos ocupantes do prédio da Samsumg em Seul. O método utilizado foi o POE, postoccupance evaluation, e consiste na coleta das opiniões dos ocupantes de um prédio após certo tempo em que o prédio está ativo e funcionando. $\mathrm{O}$ método identifica as necessidades dos ocupantes e pode ser usado para identificar melhoras em termos de design, eficiência, gerenciamento e uso prático do prédio. Idealmente todos os andares devem ser examinados, mas usualmente as medidas são limitadas devido ao tempo, trabalho e equipamentos de teste, portanto é de suma importância selecionar um andar padrão que possa representar todo o edifício. Para esta pesquisa três espaços testes foram selecionados e cada andar foi dividido em quatro zonas.

Foram medidas as iluminâncias dos planos de trabalho, utilizando digital light metre e as luminância das janelas, com color analyze de $2 D$. Obtiveram como resultados que a iluminação interna e o ambiente visual são precários e existe uma correlação significantes do conforto visual e satisfação do ocupante com as condições de iluminação e distribuição de luminância das janelas, ou seja, a iluminação natural pode melhorar a saúde psicológica e a produtividade dos ocupantes. A razão de irritação visual foi menor no verão por conta da iluminação natural, e maior no inverno e suas causas foram reflexos, escuridão e sombras, portanto o dispositivo de tela de sombreamento pode reduzir o brilho desconforto.

CHOI, J., Zhu, R (2015) constataram que o conforto dos ocupantes e a saúde fisiologia são significantemente afetados pela iluminação, temperatura, condições do ar e acústicas. Dentre estes fatores, a qualidade da iluminação é o mais importante quando considerado a saúde e conforto visual, uma vez que seus efeitos são quase que instantâneos dada a sensitividade imediata. A
Realização:

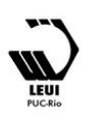




\section{$16^{\circ}$ \\ ERGODESIGN USIHC CINAHPA}

pesquisa investiga a possibilidade de usar o tamanho das pupilas do olho humano para estimar a sensação visual em um escritório de ambiente de trabalho.

Foi realizado um experimento com vinte pessoas em um protótipo de ambiente na universidade da Califórnia do Sul, em um local isolado, sem iluminação natural, equipada com 15 unidades de lâmpadas LED de $9 \mathrm{~W}$ com temperatura de cor de 2700K e a iluminância variava de 50 a 1450 lux. O nível de iluminância podia ser mudado utilizando um controle analógico. Para medir o tamanho das pupilas, foi usado um "pupilômetro", que consiste em um óculos com sensores e o tamanho das pupilas podiam ser medidos e gravados, e como parâmetro, utilizaram um tamanho padrão de pupila. Foram constatados nas cobaias sensação de escuridão e iluminância baixa e sensações de brilho e luminância alta.

O tamanho da pupila pode ser diferenciado para cada sensação visual com um nível de significância de $95 \%$ de confiança. O tamanho das pupilas mudou em média de 5,2\% a 7,4\% do tamanho da sensação neutra. Pessoas com olhos azuis, que não usam óculos mostraram uma mudança maior no tamanho das pupilas do que os outros grupos. $\mathrm{E}$ as pessoas com óculos tiveram uma variação de 1,8\%, muito abaixo da média. Os resultados são significativos pois mostram a possibilidade de se usar o tamanho das pupilas e suas taxas de variações para identificar a sensação visual dos indivíduos e assim padrões podem ser aplicados para se controlar a iluminação e mantê-la em um nível confortável.

Sun, C., Lian, Z. (2016) relacionaram a iluminação do ambiente com o nível de melanina, mucosa lacrimal e o grau de astenopia (uso de óculos quando necessário). Para isso foi criado um ambiente iluminado, onde a iluminância, a uniformidade da iluminância e a temperatura da cor poderiam ser controladas. Depois as cobaias realizaram tarefas como ler e escrever e preencheram um questionário sobre a produtividade e conforto visual. O método utilizado para medir a melatonina foi através de amostras de concentração de saliva por $16^{\circ}$ Ergodesign - Congresso Internacional de Ergonomia e Usabilidade de Interfaces Humano Tecnológica: Produto, Informações Ambientes Construídos e Transporte

$16^{\circ}$ USIHC - Congresso Internacional de Ergonomia e Usabilidade de Interfaces Humano Computador

CINAHPA | 2017 - Congresso Internacional de Ambientes Hipermídia para Aprendizagem.

radioimunoensaio (RIA), a mucosa lacrimal através de amostras da lágrima e a astenopia pelo método do ponto próximo de visão, onde se mede a menor distância dos olhos na qual o participante consegue distinguir um alvo enquanto ele é gradualmente movido para longe dos olhos.

Os resultados indicaram que os fatores selecionados tinham diferentes impactos nos fatores fisiológicos que a medida que a iluminância aumentava, o nível de melatonina decrescia significamente e a qualidade da mucosa lacrimal melhorava. Entretanto não existe uma influência da uniformidade da iluminância e da temperatura de cor nos parâmetros fisiológicos observados. A iluminância teve maior impacto seguido da correlação de temperatura de cor e por último a uniformidade de iluminância, que não teve um efeito significativo que pudesse ser identificada no trabalho.

Shamsul et al (2013) identificaram o efeito da temperatura de cor sobre o desempenho, o nível de atenção e preferências em estudantes da faculdade de medicina e ciências da saúde da Universidade de Putra, na Malásia. Os pesquisadores utilizaram luzes branca quente $(3.000 \mathrm{~K})$, branca fria $(4.000 \mathrm{~K})$ e artificial daylight $(6.500 \mathrm{~K}) \mathrm{em}$ um experimento controlado com 47 alunos de graduação daquela universidade.

O questionário OLS modificado foi utilizado para determinar a satisfação e avaliar o nível de conforto subjetivo dos estudantes ao realizares tarefas visuais, no qual consiste em doze perguntas, sendo as de 1-6 questões sobre preferências e da 7-12 sobre conforto. Para cada resposta dada as perguntas de 1-4 (declarações positivas), recebem 3 pontos para "sim", 2 para "prefiro sim", 1 para "prefiro não" e zero para "não". Para as perguntas de 5-12 (declarações negativas), recebem 3 pontos para "não", 2 para "prefiro não", 1 para "sim, sim" e zero para "sim". A luz branca fria foi apontada como aquela que proporcionou maior conforto para os estudantes, seguida da luz artificial daylight que proporciona maior desempenho na tarefa de acuidade baseada em computador no qual, demonstrado uma relação direta/inversa entre a temperatura de cor e o
Realização:
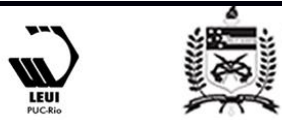


\section{$16^{\circ}$ \\ ERGODESIGN USIHC CINAHPA}

conforto visual.

\subsection{Métodos identificados}

Tabela 4. Relação dos métodos identificados

\begin{tabular}{ll} 
Método & Descrição \\
\hline $\begin{array}{l}\text { Método tradicional/ } \\
\text { Questionário de } \\
\text { resposta visual } \\
\text { (Ahamadi, N; }\end{array}$ & $\begin{array}{l}\text { Método tradicional utilizando } \\
\text { aparelho luxímetro e questionário } \\
\text { sobre resposta visual e parecer sobre } \\
\text { ah condições do espaço estudado. } \\
\text { A.,2009) }\end{array}$ \\
$\begin{array}{l}\text { Para cada questionário o autor estava } \\
\text { presente para explicar as posições } \\
\text { dos artefatos e as condições dos } \\
\text { parâmetros relacionados aos } \\
\text { questionários. As respostas foram } \\
\text { comparadas simultaneamente com as } \\
\text { medições. }\end{array}$
\end{tabular}

Método de avaliação de risco/ método padrão DIN 50356:2006 "iluminação artificial" Reinhold, K e Tint, P. (2009)

pode ser ampliado em até seis. Utiliza (não/sim) ou (corresponde as normas/não corresponde as normas).

Neste estudo, avaliou o risco dos níveis de iluminação em cinco $16^{\circ}$ Ergodesign - Congresso Internacional de Ergonomia e Usabilidade de Interfaces Humano Tecnológica: Produto, Informações Ambientes Construídos e Transporte

$16^{\circ}$ USIHC - Congresso Internacional de Ergonomia e Usabilidade de Interfaces Humano Computador

CINAHPA | 2017 - Congresso Internacional de Ambientes Hipermídia para Aprendizagem.

\begin{tabular}{ll}
\hline Musto, M; Spada, G., & luminância com ângulo de aceitação \\
larga a fim de obter mapas de & luminância de toda cena. O sistema é \\
& completado com um código de \\
& MatLab que converte um modelo de \\
& curva de calibração específica em \\
& valores de luminância. \\
& Método tradicional utilizando \\
& aparelho luxímetro para medir a \\
& luminosidade do ambiente. \\
\hline
\end{tabular}

Método POE, digital light metre e color Hwang, ocupantes de um prédio após certo T., KIM, J. T., 2011) tempo em que o prédio está ativo e funcionando. O método identifica as necessidades dos ocupantes e pode ser usado para identificar melhoras em termos de design, eficiência, gerenciamento e uso prático do prédio.

Digital light metre: Semelhante ao fotômetro, mede a intensidade luminosa de ambientes. escalas: ótima, risco tolerável; normal, risco justificado; condicional, risco não justificado; e por último, em duas etapas, o limite critico: risco inadmissível e intolerável. precisão de cor e luminância de duas
Pupilômetro (CHOI, J., Zhu, R, 2015)

É projetado um protótipo de ambiente de trabalho e fica a cargo do participante escolher a luminosidade desejada, de maneira que este consiga realizar as tarefas com o máximo de eficiência e conforto.

\begin{tabular}{|c|c|}
\hline $\begin{array}{l}\text { Método de ajuste } \\
\text { (Logadóttir, A, } \\
\text { Christofferesen, J. e } \\
\text { Fotios, S. A., 2011; } \\
\text { Korte, E. M et al., } \\
\text { 2015) }\end{array}$ & $\begin{array}{l}\text { É projetado um protótipo de } \\
\text { ambiente de trabalho e fica a cargo } \\
\text { do participante escolher a } \\
\text { luminosidade desejada, de maneira } \\
\text { que este consiga realizar as tarefas } \\
\text { com o máximo de eficiência e } \\
\text { conforto. }\end{array}$ \\
\hline
\end{tabular}

Método tradicional e

"servo-controlled rotating shutter"

(Winterbottom, M. e

Wilkins, A., 2009)
Método tradicional utilizando o aparelho luxímetro para medir a luminosidade do ambiente e método "servo-controlled rotating shutter", aparelho que mede o flicker da lâmpada, e neste caso foi programado para 104 oclusões por segundo.
Radioimunoensaio (RIA): são coletadas amostras de saliva por RIA e centrifugadas, o líquido sobrenadante é extraído e armazenado.

\author{
Método \\ HDR/MATLAB e \\ Método HDR, consiste em uma \\ método tradicional \\ câmera digital, devidamente \\ luxímetro (Bellia, L. \\ modificada e calibrada como \\ fotômetro com função de medidor de
}

\section{Radioimunoensaio (RIA), amostras de lagrima e método do ponto próximo da visão (Sun, C., Lian, Z., 2016)}

Método do ponto próximo da visão: mede-se a menor distância dos olhos na qual o participante consegue distinguir um alvo enquanto ele é gradualmente movido para longe dos olhos. superfícies dimensionais.

Consiste em um óculos com sensore medidos e gravados, e como parâmetro, utiliza-se um tamanho padrão de pupila.
Realização:

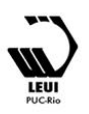




\section{$16^{\circ}$ \\ ERGODESIGN USIHC CINAHPA}

$16^{\circ}$ Ergodesign - Congresso Internacional de Ergonomia e Usabilidade de Interfaces Humano Tecnológica: Produto, Informações Ambientes Construídos e Transporte

$16^{\circ}$ USIHC - Congresso Internacional de Ergonomia e Usabilidade de Interfaces Humano Computador

CINAHPA | 2017 - Congresso Internacional de Ambientes Hipermídia para Aprendizagem.

Amostra de lágrima: o muco da lágrima é coletado por raspagem. Após a secagem e cristalização são analisadas com um microscópio.
Software FrACT/ Anéis de Landolt/ questionário OLS de sonolência de Karolinska (KSS) (Shamsul et al., 2013) modificado/ escala

Questionário OLS é utilizado para determinar a satisfação e avaliar o nível de conforto subjetivo dos estudantes ao realizares tarefas visuais, no qual consiste em doze perguntas, sendo da 1-6 questões sobre preferências e da 7-12 sobre conforto. Para cada resposta dada as perguntas de 1-4 (declarações positivas), recebem 3 pontos para "sim", 2 para "prefiro sim", 1 para "prefiro não" e zero para "não". Para as perguntas de 5-12 (declarações negativas), recebem 3 pontos para "não", 2 para "prefiro não", 1 para "sim, sim" e zero para "sim".

Escala de sonolência de Karolinska (KSS) é uma classificação subjetiva, onde cada entrevistado afirma seu atual nível de alerta em um início de escala 9 (fase de extremo alerta) e 1 (com sono, grande esforço para me manter acordado).

\begin{abstract}
Anéis de Landolt (realizado no papel). Cada entrevistado recebe um pedaço de papel branco e sobre ele, linhas de anéis de Landolt são impressas (contraste muito fraco). Os participantes têm que determinar em em cinco minutos e sem escrita no papel, as orientações corretas de todos os 96 anéis e anotar o número de anéis contados para todas as quatro orientações possíveis (aberta na parte superior, inferior, esquerda e direita).
\end{abstract}

\begin{abstract}
Software FrACT (Freiburg acuidade visual e contraste test) determina a acuidade visual e limiar contrastante através dos anéis de Landolt (mesma atividade, porém realizada em computadores).
\end{abstract}

Fonte: Elaborado pelos autores, 2016

O desconforto visual pode ser analisado de inúmeras maneiras, seja por simulação de espaços internos, onde são criados protótipos de ambientes em que a luz, sua distribuição, uniformidade, intensidade podem ser controladas tanto pelo participante como pelo pesquisador. Nestes ambientes também são realizadas tarefas, com ou sem a presença de brilho, temperatura de cor baixa ou elevada, contraste, entre outros. E assim, esses experimentos tem o objetivo de constatar a presença do desconforto visual, níveis de acuidade, estado de alerta e a preferência dos usuários.

Em relação aos outros artigos analisados, este método, utilizado por Logadóttir, A, Christofferesen, J. e Fotios, S. A., (2011) e Korte, E. M et al., (2015) foi o que mais apresentou resultados significativos, e que além de gerar conforto para os usuários, também foram constatadas economias de energia.

Apesar dos avanços tecnológicos alguns pesquisadores, como Bellia, L.; Musto, M; Spada, G., (2011) ainda utilizam de métodos tradicionais, como o caso do luxímetro, que em comparação com o método HDR, percebeu-se que não há muitas diferenças nos resultados. Outro método tradicional que foi identificado, porém em uma versão mais atualizada foi o digital light metre que é um aparelho semelhante ao fotômetro, e em conjunto com outros métodos como: Método POE e color analyze de $2 \mathrm{D}$, aplicados por Hwang, T., KIM, J. T., (2011) obtiveram resultados significantes. Porém, como já dito anteriormente, não existe o melhor ou único método, o que existe é o método mais adequado para uma determinada situação.

Alguns métodos realizados através de questionários e comparados com normas e regulamentações, podem ter efeitos subjetivos de conforto visual, como foi o caso de Ahamadi, N; Ahamadi, S. e Talib, A., (2009) e Reinhold, K e Tint, P. (2009). Estes, mostram a relação existente da qualidade da iluminação e o desconforto, porém não explicam de forma efetiva sua influência, e do porquê de algumas pessoas terem respostas e sensações diversas. Nestes casos, o ideal é a utilização de mais de um método que possa comprovar ou trazer alguma outra informação para se chegar em um resultado mais preciso, como Shamsul et al., (2013); Hwang, T., KIM, J. T., 
(2011); Winterbottom, M. e Wilkins, A., (2009) fizeram.

No caso dos pesquisadores CHOI, J., Zhu, R, (2015), estes conseguiram alcançar resultados precisos utilizando de apenas um método, o pupilômetro. E Sun, C., Lian, Z., (2016) recorreu a métodos de análises de salivas e lágrimas, em conjunto com o método do ponto próximo da visão.

\section{Conclusão}

Este trabalho identificou e analisou através de uma revisão sistemática bibliográfica um conjunto de métodos para análise do desconforto visual. $\mathrm{O}$ intuito foi de pesquisar, organizar e sintetizar em um único trabalho, as possíveis maneiras de medir o desconforto visual em ambientes de trabalho, para que seja possível propor melhorias na qualidade de vida de trabalhadores, combatendo assim, problemas físicos e/ou cognitivos.

Alguns métodos foram encontrados em mais de um trabalho, outros utilizaram um conjunto de dois ou três métodos para atingir o objetivo. Isso pode se dar ao fato da complexidade e das várias maneiras possíveis de se medir o desconforto, tendo em vista que este, em muitos casos, é subjetivo.

Sendo assim, é importante conhecer os métodos que vêm sendo utilizados por diversos pesquisadores do mundo, que criaram e utilizaram de métodos muito diversos cada qual com suas abordagens, para que estes possam vir a serem utilizados em futuros trabalhos. Com isso é preciso enfatizar a importância da utilização destes métodos na criação e/ou correção dos ambientes de trabalho, para priorizar o conforto, evitando possíveis riscos à saúde de trabalhadores.

\section{BIBLIOGRAFIA}

AHMAD, N.; AHMAD, S. Sh; TALIB, A. Illuminance distributions, visual response and limits for conservation of exhibits in Admiral Cheng Ho Gallery, Malaysia. In: Computers \& Informatics (ISCI), 2011 IEEE Symposium on. $16^{\circ}$ Ergodesign - Congresso Internacional de Ergonomia e Usabilidade de Interfaces Humano Tecnológica: Produto, Informações Ambientes Construídos e Transporte

$16^{\circ}$ USIHC - Congresso Internacional de Ergonomia e Usabilidade de Interfaces Humano Computador

CINAHPA | 2017 - Congresso Internacional de Ambientes Hipermídia para Aprendizagem.
BELLIA, Laura; MUSTO, Marilena; SPADA, Gennaro. Illuminance measurements through HDR imaging photometry in scholastic environment. Energy and buildings, v. 43, n. 10, p. 2843-2849, 2011.

BOYCE, P. R. Human Factors in lighting. $2^{\mathrm{a}}$ ed: Taylor \& Francis. London and New York, 2003.

CHOI, Joon-Ho; ZHU, Rui. Investigation of the potential use of human eye pupil sizes to estimate visual sensations in the workplace environment. Building and Environment, v. 88, p. 73-81, 2015.

FERRARI, D. A. et al. Conceitos de conforto, estudos e relação com o design e a ergonomia: análise qualitativa da iluminação em uma indústria de fertilizantes. In: Marizilda dos Santos Menezes; Mônica Moura. (Org.). Rumos da pesquisa no design contemporâneo: relação tecnologia $\mathrm{x}$ humanidade. 1ed.São Paulo: Estação das Letras e Cores, 2013, v. 1, p. 129-146.

HWANG, Taeyon; KIM, Jeong Tai. Effects of indoor lighting on occupants' visual comfort and eye health in a green building. Indoor and Built Environment, p. 1420326X10392017, 2010.

IACOMUSSi, Paola, et al. Visual Comfort with LED Lighting. 6th International Building Physics Conference, IBPC, Elsevier, Energy Procedia v. 78, p. $729-734,2015$.

KORTE, Elisabeth M. de et al. Personal environmental control: Effects of pre-set conditions for heating and lighting on personal settings, task performance and comfort experience. Building and Environment, v. 86, p. 166-176, 2015.

LAMBERTS, Roberto; DUTRA, Luciano. PEREIRA, FOR. Eficiência energética na arquitetura, 1997.

LOGADÓTTIR, Ásta; CHRISTOFFERSEN, Jens; FOTIOS, S. A. Investigating the use of an adjustment task to set the preferred illuminance 


\section{$16^{\circ}$ \\ ERGODESIGN USIHC CINAHPA}

in a workplace environment. Lighting Research and Technology, v. 43, n. 4, p. 403-422, 2011.

OLIVEIRA, Gilberto Rangel de; MONT'ALVÃO, Claudia. Some considerations about human factors in environment design: what interior design and architects say. Proceeding of the human factors and ergonomics society 58th anual meeting, 2014.

REINHOLD, K.; TINT, P. Lighting of workplaces and health risks. Elektronika ir Elektrotechnika, v. 90, n. 2, p. 11-14, 2015.

RODRÍGUEZ, J.M; CASTILLA, M.; ÁLVAREZ, J.D.; RODRÍGUEZ, F.; BERENGUEL, M. A fuzzy controller for visual comfort inside a meeting room. 23ed Mediterranean conference on control and automation (MED), june 16-19, 2015. Torremolinos, Espanha.

SANTOS, Flavio Anthero Nunes Vianna dos. Nota de aula disciplina: Design, Método e Fatores Humanos - CURSO DE PÓS-GRADUAÇÃO EM DESIGN PPGD - Mestrado Métodos para fatores humanos - Florianópolis, UDESC - Universidade do Estado de Santa Catarina, 06 de setembro de 2016.

SLATER, Keith. Human Comfort. Springfield (Illinois): Charles C. Thomas, 1985.

SCHMID, Aloísio Leoni. A idéia de conforto: reflexões sobre o ambiente construído.

Pactoambiental, 2005.

VAN DER LINDEN, Júlio Carlos de Souza; GUIMARÃES, Lia Buarque de Macedo; TABASNIK, Rafael . Conforto e Desconforto: são construtos opostos?. In: $3^{\circ}$ Congresso Internacional de Pesquisa em Design, 2005, Rio de Janeiro. Anais do $3^{\circ}$ Congresso Internacional de Pesquisa em Design, 2005.

WINTERBOTTOM, Mark; WILKINS, Arnold. Lighting and discomfort in the classroom. Journal of Environmental Psychology, v. 29, n. 1, p. 63-75, 2009. $16^{\circ}$ Ergodesign - Congresso Internacional de Ergonomia e Usabilidade de Interfaces Humano Tecnológica: Produto, Informações Ambientes Construídos e Transporte

$16^{\circ}$ USIHC - Congresso Internacional de Ergonomia e Usabilidade de Interfaces Humano Computador

CINAHPA | 2017 - Congresso Internacional de Ambientes Hipermídia para Aprendizagem.

\section{Agradecimentos}

Ao Programa de Bolsas de Monitoria de PósGraduação (PROMOP/UDESC) que possibilita a bolsa de estudos durante o período do mestrado. 